\title{
THE CONCEPT OF AN INTEGRATED INFORMATION SYSTEM FOR PLANNING OF FLEET OPERATION IN THE ARCTIC
}

Timofeev O. Ya., Tarovik O. V., Topaj A. G.

Krylov State Research Centre (St. Petersburg, Russian Federation)

Mironov E. U., Frolov S. V.

Arctic and Antarctic Research Institute (St. Petersburg, Russian Federation)

Buyanov A. S.

Central Marine Research and Design Institute (St. Petersburg, Russian Federation)

Gorbachev M. A.

Scientific Logistics Center LLC (Moscow, Russian Federation)

Bengert A. A.

Northern Sea Route Directorate of the State Atomic Energy Corporation Rosatom (Moscow, Russian Federation)

The article was received on December 24, 2018

\begin{abstract}
There are several reasons for the multiple increase in intensity of Arctic shipping in the near future. This makes quite relevant the development of tools and algorithms for information support of navigation in this complex region.

In this article, we describe the concept of an integrated information system for planning the operation of cargo ships and icebreakers in the Arctic. The planning task is divided into three levels: operational, tactical and strategic. The goal of operational-tactical planning is to increase the efficiency of the maritime transport system, taking into account the requirements for ice navigation safety. This task includes both the optimization of vessel routes and the development of an optimal plan for their icebreaking support throughout the region. Such a plan includes geographic points and dates for the convoy formation and splitting up, as well as the convoy composition, recommended routes in ice, etc.

The structure of the Centralized system for tactical and operational planning of shipping in the Arctic includes four main domains. The "Ships" Domain includes the software infrastructure for the generation and storage of information models of vessels, icebreakers, as well as computational models of vessel movement in ice. The "Passages" Domain is used to store data on scheduled, current and completed passages of ships and icebreakers. The "Nature" Domain describes and displays the environmental parameters. It contains both the static information elements (navigation maps and databases of navigation conditions) and the components for operational monitoring and forecasting of weather and ice cover dynamics. The ship onboard recorders of voyage data and environmental parameters play a special role in the System, since they allow collecting big data to improve various computational algorithms. The services joined in the "Planning" Domain from the intellectual core of the System; they are related to the methods of automatic decision making and their implementation is possible with the use of modern technologies, such as knowledge bases and machine learning techniques.

The article highlights the main groups of scientific and methodological problems that challenges the implementation of the proposed System. They are: (1) spatial logistic planning of ships' and icebreakers' operation at the tactical and operational levels; (2) the need to improve the accuracy as well as the horizon of operational ice forecasts; (3) the development of a robust computational model to predict the parameters of vessel and convoy movement in ice, taking into account all ice features that determine ship performance.

Implementation of the System will improve the economic efficiency and safety of Arctic shipping by means of the centralized planning of ships and icebreakers operation.
\end{abstract}

Keywords: Arctic fleet, economic efficiency of shipping, icebreakers, ice-going vessels, fleet planning, planning levels, scheduling, ice routing, machine learning, ship on-board recorder.

\section{Bibliographic description of the article}

Timofeev O. Ya., Tarovik O. V., Topaj A. G., Mironov E. U., Frolov S. V., Buyanov A. S., Gorbachev M. A., Bengert A. A. The concept of an integrated information system for planning of fleet operation in the Arctic. Arctic: Ecology and Economy, 2019, no. 1 (33), pp. 129-143. DOI: 10.25283/2223-4594-2019-1-129-143. (In Russian).

(c) Timofeev O. Ya., Tarovik O. V., Topaj A. G., Mironov E. U., Frolov S. V., Buyanov A. S., Gorbachev M. A., Bengert A. A., 2019 


\section{Information about the authors}

Timofeyev Oleg Yakovlevich, Doctor of Technical Sciences, Deputy General Director of shipbuilding and marine technology, Krylov State Research Centre (44, Moskovskoe shosse, St. Petersburg, Russia, 196158), e-mail: o_ timofeev@ksrc.ru.

Tarovik Oleg Vladimirovich, $\mathrm{PhD}$ of Technical Sciences, Senior research engineer, Krylov State Research Centre (44, Moskovskoe shosse, St. Petersburg, Russia, 196158), e-mail: tarovik_oleg@mail.ru.

Topaj Aleksandr Grigorevich, Doctor of Technical Sciences, Leading research engineer, Krylov State Research Centre (44, Moskovskoe shosse, St. Petersburg, Russia, 196158), e-mail: alex.topaj@gmail.com.

Mironov Yevgeny Uarovich, Doctor of Geographical Sciences, Chief Researcher - Head of the Ice Regime and Forecast Department, Arctic and Antarctic Research Institute (38, Bering street, St. Petersburg, Russia, 199397), e-mail: mir@aari.ru.

Frolov Sergey Victorovich, Head of the Ice Navigation Laboratory, Arctic and Antarctic Research Institute (38, Bering street, St. Petersburg, Russia, 199397), e-mail: svf@aari.nw.ru.

Buyanov Aleksandr Sergeevich, PhD of Economic Sciences, Deputy Director General for Research, Development, Economics and Ecology of Maritime Transport. Central Marine Research and Design Institute (6A, Kavalergardskaya street, St. Petersburg, Russia, 191015), e-mail: buyanovas@cniimf.ru.

Gorbachev Maksim Aleksandrovich, PhD of Technical Sciences, Head of Software Development Department, Scientific Logistics Center LLC (28, p. 2, Goncharnaya street, Moscow, Russia, 115172), e-mail: mg@n-l-c.ru.

Bengert Aleksandr Aleksandrovich, Deputy Head of department, Northern Sea Route Directorate of the State Atomic Energy Corporation Rosatom (24, Bolshaya Ordynka, Moscow, Russia, 119017), e-mail: aabengert@ rosatom.ru.

\section{References}

1. Vauraste T. Icepool - Holistic use of global icebreaker fleet. Maritime cluster in the Baltic Sea region and beyond. [S. I.], 2016, P. 104-105.

2. International Code for Ships Operating in Polar Waters. Guidance on Methodology for assessing operational capabilities and limitations in ice. Polar Operational Limit assessment Risk Indexing System (POLARIS). [S. I.], 6 June 2016. MSC.1/Circ.1519.

3. Christiansen M., Fagerholt K., Nygreen B., Ronen D. Maritime Transportation. Handbooks in Operations Research and Management Science. C. Barnhart, G. Laporte (eds.). North Holland, Amsterdam, 2007, pp. 189-284.

4. Bakharev A. A., Kosorotov A. V., Krest'yantsev A. B., Tarovik O. V., Topazh A. G. lerarkhiya urovnei prinyatiya reshenii $v$ imitatsionnom modelirovanii morskikh perevozok. [The hierarchy of decision levels in the computer simulation of maritime transportation]. Tr. konf. IMMOD-2015. Vol. 1. Moscow, IPU RAN, 2015, pp. 34-39. (In Russian).

5. Tarovik O. V., Topazh A. G., Krest'yantsev A. B., Kondratenko A. A. Modelirovanie sistem arkticheskogo morskogo transporta: osnovy mezhdistsiplinarnogo podkhoda i opyt prakticheskikh rabot. [Arctic Marine Transport System Simulation: Multidisciplinary Approach Fundamentals and Practical Experience]. Arktika: ekologiya i ekonomika, 2017, no. 1 (25), pp. 86101. (In Russian).

6. Frolov S. V. Vliyanie orientatsii narushenii sploshnosti l'da na effektivnost' dvizheniya sudov v arkticheskom basseine $v$ letnii period. [The influence of orientation of ice leads on the efficiency of vessel navigation in the Arctic in summer period]. Problemy Arktiki i Antarktiki, 2013, no. 3 (97), pp. 35-45. (In Russian).
7. Adamovich N. M., Buzuyev A. Ya., Fedyakov V. E. The empiric model of vessel movement in the ice and generalization of the experience of the model usage in hydrometeorological support of shipping in the Arctic. Proceedings of POAC-1995. Vol. 2. Murmansk, 1995, pp. 30-40.

8. Brovin A. I., Klyachkin S. V., Bhat S. U. Application of an empirical-statistical model of ship motion in ice to new types of icebreakers and ships. Proceedings of OMAE-1997. Vol. 4. Yokohama, Japan, 1997, pp. 43-49.

9. Montewka J., Sinclair H., Kujala P., Haapala J., Lensu M. Modelling ship performance in ice using Bayesian Networks. Proceedings of POAC-2013. spoo, Finland, 2013, 12 p.

10. Bushuev A. V., Volkov N. A., Gudkovich Z. M., Novikov Yu. R., Prokof'ev V. A. Avtomatizirovannaya ledovo-informatsionnaya sistema dlya Arktiki (ALISA). [Automated Ice Information System for the Arctic]. Tr. AANII, 1977, vol. 343, pp. 29-47. (In Russian).

11. Mironov E. U., Ashik I. M., Brestkin S. V., Smirnov V. G. Adaptiruemyi kompleks monitoringa i prognozirovaniya sostoyaniya atmosfery i gidrosfery. [Adaptable complex for monitoring and forecasting the state of the atmosphere and hydrosphere]. Problemy Arktiki i Antarktiki, 2009, no. 3 (83), pp. 88-97. (In Russian). 12. Tarovik O. V., Topazh A. G., Krest'yantsev A. B., Kondratenko A. A., Zaikin D. A. Kompleksnaya imitatsionnaya model' morskoi transportno-tekhnologicheskoi sistemy platformy "Prirazlomnaya". [Comprehensive Simulation Model of Marine Transport and Support System for "Prirazlomnaya" Platform]. Arktika: ekologiya i ekonomika, 2017, no. 3 (27), pp. 86-103. (In Russian). 
13. Rybii V. V., Kazunin D. V., Timofeev O. Ya., Belyashov V. A., Pronyashkin A. A., Kazunin I. D. Rossiiskaya ledovaya informatsionnaya sistema (LIS) - zalog uspeshnogo osvoeniya Arktiki. [Russian Ice Information System (LIS) - the key to successful development of the Arctic]. Mor. vestn, 2016, no. 4 (60), pp. 63-67. (In Russian).

14. Frolov S. V., Klein A. E., Tret'yakov V. Yu. Rezul'taty ispol'zovaniya tsifrovogo televizionnogo kompleksa dlya izmerenii tolshchiny l'da $v$ Arkticheskom basseine v 2004-2005 gg. [The results of using a digital television complex for measuring ice thickness in the Arctic basin in 2004-2005]. Problemy
Arktiki i Antarktiki, 2007, no. 1 (75), pp. 123-127. (In Russian).

15. Tret'yakov V. Yu., Frolov S. V., Klein A. E. Metodika rascheta skorosti slozheniya kanala $v$ ledyanom pokrove po dannym televizionnykh snimkov. [The method to calculate the rate of closing of channel in ice cover based on television imagery data]. Meteor. vestn., 2010, no. 2 (7), pp. 12-29. (In Russian).

16. Pronyashkin A. A., Karulin E. B., Kazantsev M. A. Ledovaya informatsionnaya sistema dlya Arkticheskogo shel'fa. [Ice information system for the Arctic shelf]. Tr. Mezhdunar. konf. Offshore Marintec Russia-2018. 2-5 oktyabrya 2018 g. St. Petersburg, 2018. (In Russian). 
DOI: 10.25283/2223-4594-2019-1-129-143

УДК 656.61

\title{
КОНЦЕПЦИЯ ЦЕНТРАЛИЗОВАННОЙ ИНФОРМАЦИОННОЙ СИСТЕМЫ ДЛЯ ПЛАНИРОВАНИЯ РАБОТЫ ФЛОТА В АРКТИКЕ
}

\author{
О. Я. Тимофеев, О. В. Таровик, А. Г. Топаж \\ ФГУП «Крыловский государственный научный центр» (Санкт-Петербург, Российская Федерация)
}

\section{Е. У. Миронов, С. В. Фролов}

ФГБУ «Арктический и антарктический научно-исследовательский институт» (Санкт-Петербург, Российская Федерация)

\section{А. С. Буянов}

АО «Центральный ордена Трудового Красного Знамени научно-исследовательский и проектноконструкторский институт морского флота» (Санкт-Петербург, Российская Федерация)

\section{М. А. Горбачев}

ООО «Научный логистический центр» (Москва, Российская Федерация)

\author{
А. А. Бенгерт \\ Дирекция Северного морского пути ГК «Росатом» (Москва, Российская Федерация) \\ Статья поступила в редакцию 24 декабря 2018 г.
}

Описана концепция создания единой системы для мониторинга и планирования работы судов и ледоколов в Арктике. Выполнена постановка задачи планирования на трех уровнях: оперативном, тактическом и стратегическом. Приведены предпосылки создания системы, описана ее принципиальная структура, перечислены основные научно-методические сложности ее реализации, а также имеющийся научнотехнический задел отечественных компаний. Внедрение системы позволит повысить экономическую эффективность и безопасность судоходства в арктическом регионе за счет иентрализованного планирования операций судов и ледоколов.

Ключевые слова: арктический флот, экономическая эффективность судоходства, ледоколы, суда ледового плавания, планирование работы флота, уровни планирования, составление расписаний, ледовая маршрутизация, машинное обучение, судовой бортовой регистратор.

\begin{abstract}
Введение
В последние годы многие судоходные компанииоператоры активно развивают собственные системы мониторинга и оперативного планирования работы флота. Практическая реализация таких решений производится в виде ситуационных центров, которые оснащаются оборудованием для сбора, анализа и визуализации различной оперативной информации. Целью внедрения таких технологий является ускорение и улучшение качества оперативных
\end{abstract}

() Тимофеев О. Я., Таровик О. В., Топаж А. Г., Миронов Е. У., Фролов С. В., Буянов А. С., Горбачев М. А., Бенгерт А. А., 2019 решений, что в конечном счете влияет на экономическую эффективность перевозок.

Как правило, развитие ситуационных центров начинается с реализации функций мониторинга и контроля, что позволяет отслеживать текущее состояние судов (положение в пространстве, объемы судовых запасов, различные события и т. д.) и автоматизировать процессы подготовки множества формальных документов и отчетов. Эти мероприятия позволяют достаточно быстро повысить эффективность операционной деятельности судоходной компании. Следующим этапом является реализация функций планирования работы судов и объектов ин- 
фраструктуры на различных временных горизонтах: стратегическом (десятилетия), тактическом (сезон) и оперативном (сутки). Это позволяет выявить дополнительные резервы повышения эффективности судоходства за счет оптимизационного планирования работы флота. В то время как задачи визуализации и учета могут быть решены с применением в основном существующих технологий и стандартного оборудования, функции планирования необходимо адаптировать под задачи и бизнес-процессы каждой конкретной компании. Для этого необходимы индивидуальные и во многом уникальные разработки в области логистического планирования, алгоритмизации и программного обеспечения.

Для компании-судовладельца зачастую достаточна реализация только функций мониторинга и учета, однако применительно к арктическому судоходству в целом в настоящее время сложились серьезные предпосылки для реализации именно функций централизованного планирования. Суть такого подхода состоит в создании единой «советующей» системы для мониторинга и оперативного планирования работы судов и ледоколов в Арктике независимо от их принадлежности к той или иной компании. Возможность и целесообразность создания единой информационной компьютерной системы для планирования работы флота в Арктике (далее - Система) обусловлена целым рядом предпосылок. В настоящей статье приведена общая постановка задачи планирования и описаны характерные уровни плановых решений, предложена для обсуждения общая функциональная структура подобной Системы, перечислены основные сложности ее разработки и внедрения, а также описан имеющийся научно-технический задел, на основе которого возможна ее реализация.

\section{Предпосылки создания Системы}

Одной из главных причин, обуславливающих целесообразность создания единой системы для планирования работы флота в Арктике, является кардинальное увеличение интенсивности судоходства по Северному морскому пути (СМП). Главным драйвером развития Арктики как маршрута ресурсных перевозок является рост грузопотоков добычных проектов. Согласно планам развития арктических месторождений экспорт ресурсов через СМП должен возрасти с 17-18 млн т в 2018 г. до 70-80 млн т к 2025-2030 гг.' Помимо этого существуют перспективы использования СМП как транзитного коридора между Азией и Европой. Конечно, СМП сегодня не может рассматриваться как полноценный конкурент южному морскому пути, однако при определенных условиях северный маршрут может быть выгоден как грузоотправителям, так и судовладельцам. С точки зрения экономической эффективности

\footnotetext{
1 Атомфлот прогнозирует объем грузоперевозок по СМП по итогам года на уровне 17-18 млн т. - URL: https://tass.ru/ ekonomika/5608441.
}

транзитных перевозок в сложных навигационных условиях СМП фактор согласованной работы транспортного и ледокольного флотов оказывается достаточно важным. Помимо чисто экономических причин для азиатских и европейских стран использование СМП позволяет снизить геополитические риски, давая альтернативу перевозкам через Суэцкий канал. Дополнительный интерес Китая и Южной Кореи к развитию СМП связан еще и с тем, что эти страны являются лидерами мирового транспортного судостроения и, очевидно, рассчитывают в будущем строить дорогостоящий арктический флот. По этим причинам многие научные и информационно-аналитические издания признают СМП одной из наиболее перспективных транспортных артерий XXI в. Растущая роль СМП в мировой торговле и увеличение численности судов ледового класса потребует выработки качественно новых решений в сфере планирования работы флота в условиях арктической навигации.

Вторая причина заключается в появлении новых компьютерных технологий, благодаря которым потенциально возможна реализация новых принципов интеллектуального планирования работы флота. Дело в том, что, несмотря на большие технические возможности современных ледоколов и судов ледового плавания, полное раскрытие их транспортного потенциала возможно при условии внедрения качественно новых средств информационного обеспечения арктического судоходства. Речь идет не только о дальнейшем развитии имеющихся сервисов оптимизации маршрутов движения судов во льдах на основе спутниковых данных и ледовых прогнозов, но и о возможностях создания новых методов оперативного планирования операций проводки судов ледоколами, которые будут особенно актуальны в условиях дефицита ледокольного ресурса. Для информационной поддержки процессов планирования флота могут также использоваться различные алгоритмические решения, нейронные сети, технологии больших данных (big data) и другие современные подходы. Очевидно, что поскольку в ближайшие годы численность судов ледового плавания будет увеличиваться, планирование их работы в ручном режиме станет крайне затруднительным, и роль компьютерных решений в этой сфере существенно возрастет.

Третья предпосылка связана с тем, что современные суда, предназначенные для круглогодичной работы в Арктике, являются очень дорогостоящими. Они характеризуются повышенной массой корпуса, специальным пропульсивным комплексом, применением электроэнергетической установки повышенной мощности, а также целым рядом судовых систем для работы в условиях низких температур. В результате увеличиваются как строительная стоимость судна, так и эксплуатационные затраты. Поэтому даже незначительное улучшение таких показателей, как длительность рейса и расход топлива, позволит по- 


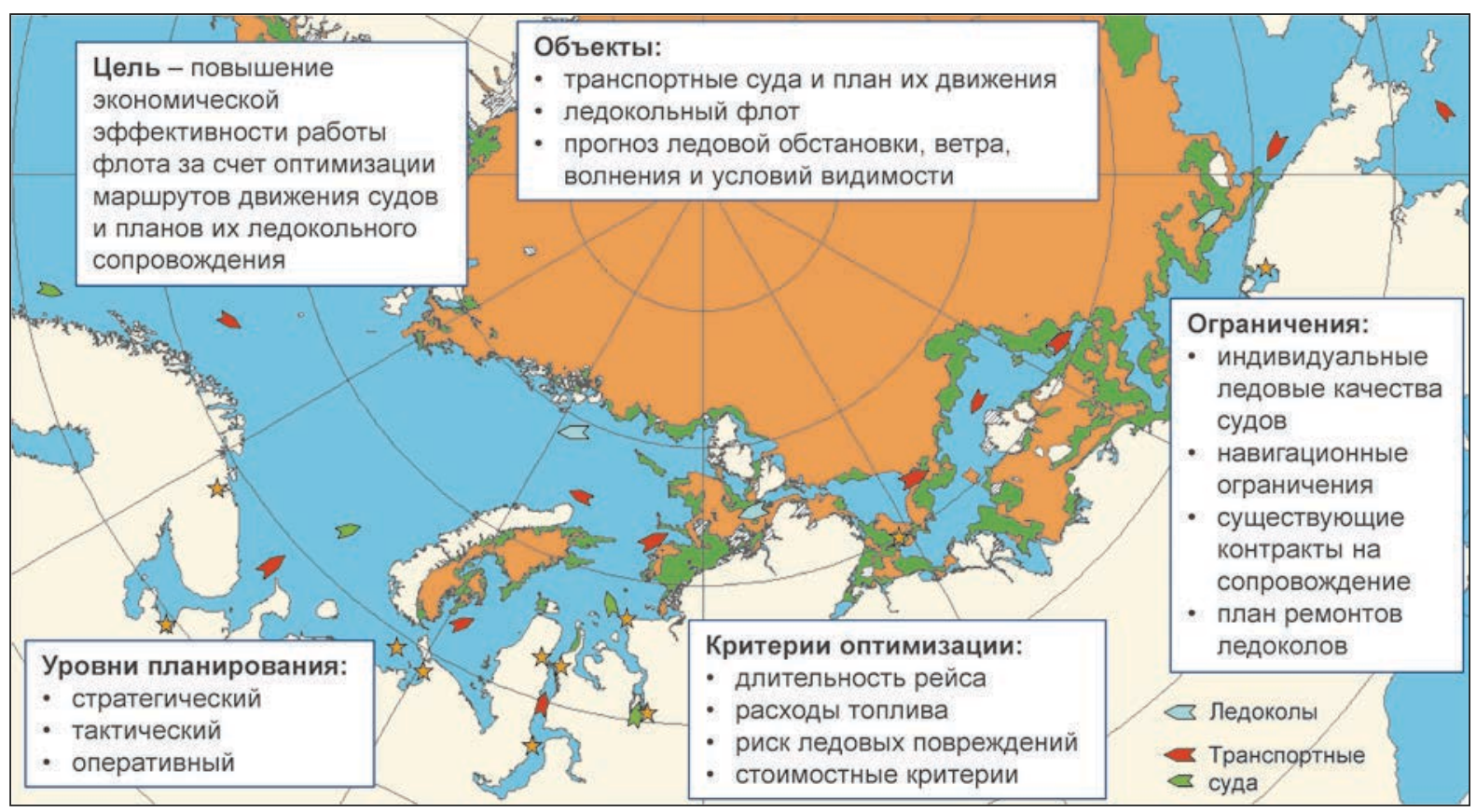

Рис. 1. Общая схема задачи планирования работы судов и ледоколов в Арктике

Fig. 1. General description of the task of planning ships and icebreakers operation in the Arctic

лучить существенный экономический эффект. Помимо этого отдельными важными задачами являются снижение повреждаемости корпусов и движителей во льдах, а также повышение надежности работы арктической транспортной линии в целом.

Четвертая причина состоит в наличии положительного прецедента - опыта работы единой межведомственной системы обеспечения мореплавания по СМП, функционировавшей в СССР с середины 1970-х до конца 1980-х годов. В рамках этой системы были созданы штабы морских операций западного и восточного секторов Арктики, в полномочия которых входил весь комплекс вопросов оперативного обеспечения судоходства, расстановки ледоколов, а также имелась возможность интеграции и обобщения гидрометеорологической и навигационной информации, получаемой из разных источников. Этот опыт продемонстрировал эффективность централизованного планирования работы арктического флота. В настоящее время принципы централизованного планирования реализуются редко, несмотря на их эффективность при решении задач стратегического уровня. Это обусловлено особенностями современной экономической системы, для которой характерно наличие множества хозяйствующих субъектов с различными и зачастую противоположными интересами. Тем не менее обеспечение суходоходства в ледовых условиях - один из немногих примеров, где интересы практически всех участников сходятся на необходимости облегчения условий навигации. В подтверждение этого тезиса можно привести идеи иностранных коллег о возможности совместного использования ледоколов на
Балтике и организации единого сервиса для оптимального планирования их работы [1]. Таким образом, положительный опыт прошлых лет может быть воплощен в современных условиях на качественно новом уровне с учетом возможностей компьютерных и спутниковых технологий. Представляется, что концентрация управленческих функций в одних руках и создание эффективного механизма организации плавания судов в Арктике будут входить в компетенции Дирекции Северного морского пути государственной корпорации «Росатом» как единого инфраструктурного оператора.

\section{Постановка задачи и уровни планирования}

Общая схема задачи планирования работы судов и ледоколов в Арктике приведена на рис. 1. Общая цель планирования заключается в повышении экономической эффективности работы флота за счет оптимизации маршрутов движения судов и планов их ледокольного сопровождения. Результатом решения задачи планирования должен быть комплекс следующих рекомендаций:

- точки и времена сбора и роспуска караванов, состав караванов, а также ледоколы сопровождения; - рекомендованный маршрут самостоятельного плавания для каждого судна (включая ледоколы), а также прогнозируемые длительности рейсов и расходы топлива;

- назначенные регионы работы ледоколов для облегчения ледовой обстановки.

Для получения таких рекомендаций в задаче планирования должны быть рассмотрены следующие объекты: 
- транспортные суда, подходящие к арктическим водам или уже находящиеся в них, и расписание их движения, включающее плановое время прибытия в порты назначения или время выхода из арктических вод;

- ледоколы и операции, выполняемые ими в данный момент;

- текущая, прогностическая или архивная информация о ледовой обстановке, ветре, волнении и видимости;

- план ремонтов и докований ледоколов и вспомогательных судов.

Роль ограничений в описанной задаче выполняет комплекс следующих факторов:

- индивидуальные ходовые качества судов, включая их технические возможности в части ледовой ходкости, ходкости на волнении (ограничения по штормованию), ледовой прочности корпуса (ледовый класс), а также текущее состояние износа корпуса и движителей для судов высокого ледового класса;

- навигационные ограничения, включая наличие промеров глубин и покрытие акваторий сервисами спутникового зондирования поверхности Земли;

- существующие контракты на ледокольное сопровождение, которые будут определять степень приоритета удовлетворения заявок судов на проводку (если организационной моделью работы Системы будет предусмотрено наличие таких ограничений);

- план докований, ремонтов и технических обслуживаний ледоколов, который особенно актуален для задач планирования на тактическом уровне.

В роли критериев оптимизационной задачи по формированию плана работы судов и ледоколов могут приниматься различные параметры или их комбинации, которые определяют экономическую эффективность перевозок. Например, в условиях зимней навигации для судов высокого ледового класса в качестве критерия можно использовать длительность рейса. Для транзитных плаваний в летний период могут дополнительно учитываться расходы топлива, а также возможность привлечения ледоколов. В качестве альтернативного критерия выступает уровень риска ледовой эксплуатации [2], характеризующий вероятность повреждения корпуса и движителей судна и связанные с этим стоимости и длительности ремонтов. При необходимости каждый из этих критериев или каждая их комбинация могут быть приведены к единому стоимостному показателю, учитывающему фрахт судна, расходы на топливо, затраты на ледокол, риски повреждений и другие составляющие. Это позволяет привязать каждую операцию судна или каждый альтернативный сегмент маршрута во льдах к условному денежному эквиваленту, что дает возможность оптимизировать как маршруты судов, так и расписание работы флота путем минимизации некоего стоимостного показателя.
В соответствии с общими принципами морской логистики [3] в рассматриваемой задаче можно выделить три уровня планирования: стратегический, тактический и оперативный [4]. На каждом из них постановка задачи будет видоизменяться. Отличаться будут как уровень детальности описания различных процессов и ограничений, так и необходимые исходные данные, применяемые методы решения и получаемые результаты (табл. 1).

На стратегическом уровне производится планирование состава ледокольного и транспортного флотов на десятки лет вперед. В зависимости от целей такого планирования могут учитываться различные сценарии изменения ледовой обстановки (долгосрочные климатические прогнозы, типизированные архивные данные, годы-аналоги и т. д.), альтернативные сценарии изменения грузопотоков и состава транспортного флота, а также множество элементов судоходной инфраструктуры (навигационное и гидрографическое обеспечение, связь и коммуникации, портовая инфраструктура, аварийно-спасательные и лоцманские службы, нормативная база и пр.). Для решения задач стратегического планирования необходимо использовать комплекс технико-экономических моделей, методы укрупненного логистического планирования и имитационное моделирование, которое позволяет учитывать и анализировать эффекты взаимодействия природных, технологических и транспортных процессов. Стратегическое планирование является одним из основных механизмов, с использованием которого могут быть обоснованы экономически эффективные решения, направленные на успешную работу арктической транспортной системы в целом. Высокие темпы увеличения знаний делают стратегическое планирование единственным способом прогнозирования будущих проблем и возможностей. Как показывает опыт разработки моделей такого уровня [5], несмотря на упрощенный характер в стратегических моделях должны учитываться и элементы планирования на более низких уровнях, такие как планирование рейсов, разрешение различных конфликтных ситуаций на оперативном уровне и т. п. Таким образом, стратегическое планирование представляет интерес с точки зрения формирования концепции долгосрочного развития ледокольного и транспортного флотов, что безусловно является востребованной задачей. Однако оно не имеет прямого отношения к оперативному обеспечению судоходства. Поэтому модели стратегического уровня, заслуживающие отдельного рассмотрения, далее подробно не анализируется.

Тактическое планирование работы флота осуществляется на сезон, навигацию или целый год. Основной задачей является расстановка ледоколов, определение районов и временных интервалов для ледокольного сопровождения рейсов, запланированных на данном временно́м горизонте, и определение очередности проводки судов. Для различных 
Таблица 1. Уровни планирования работы флота транспортных судов и ледоколов

\begin{tabular}{|c|c|c|c|}
\hline $\begin{array}{c}\text { Уровень } \\
\text { планирования }\end{array}$ & Исходные данные & $\begin{array}{c}\text { Инструменты и методы } \\
\text { решения }\end{array}$ & $\begin{array}{l}\text { Основные } \\
\text { результаты }\end{array}$ \\
\hline $\begin{array}{l}\text { Стратегический } \\
\text { (десятки лет) }\end{array}$ & $\begin{array}{l}\text { Прогноз динамики } \\
\text { грузопотоков } \\
\text { Климатические сценарии } \\
\text { Концепция развития } \\
\text { транспортного флота }\end{array}$ & $\begin{array}{l}\text { Технико-экономические модели } \\
\text { Динамическое имитационное } \\
\text { моделирование } \\
\text { Методы укрупненного } \\
\text { планирования перевозок }\end{array}$ & $\begin{array}{l}\text { Структура и состав } \\
\text { необходимого флота } \\
\text { Характеристики } \\
\text { инфраструктуры }\end{array}$ \\
\hline $\begin{array}{l}\text { Тактический } \\
\text { (год, сезон, } \\
\text { навигация) }\end{array}$ & $\begin{array}{l}\text { Состав ледокольного } \\
\text { флота } \\
\text { План рейсов } \\
\text { транспортных судов } \\
\text { Долгосрочный прогноз } \\
\text { ледовой обстановки }\end{array}$ & $\begin{array}{l}\text { Логистическое планирование } \\
\text { рейсов } \\
\text { Алгоритмы оптимальной } \\
\text { маршрутизации } \\
\text { Математическое планирование } \\
\text { операций }\end{array}$ & $\begin{array}{l}\text { Расстановка } \\
\text { ледоколов, районы } \\
\text { и временные интервалы } \\
\text { сопровождения } \\
\text { Ориентировочные } \\
\text { опорные маршруты } \\
\text { движения }\end{array}$ \\
\hline $\begin{array}{l}\text { Оперативный } \\
\text { (несколько } \\
\text { суток) }\end{array}$ & $\begin{array}{l}\text { Текущее положение судов } \\
\text { Спутниковый мониторинг } \\
\text { льдов } \\
\text { Оперативные прогнозы } \\
\text { погоды и ледовой } \\
\text { обстановки }\end{array}$ & $\begin{array}{l}\text { Алгоритмы оперативного } \\
\text { перепланирования маршрутов } \\
\text { движения } \\
\text { База знаний о приемах } \\
\text { ледокольного сопровождения }\end{array}$ & $\begin{array}{l}\text { Детальный } \\
\text { оперативный план } \\
\text { работы судов } \\
\text { и ледоколов } \\
\text { Рекомендованные } \\
\text { маршруты движения }\end{array}$ \\
\hline
\end{tabular}

судов могут быть определены возможные районы и сроки безледокольной навигации, а также рекомендованные опорные маршруты движения. Дополнительно может также выполняться оценка прогнозируемых времен рейсов и затрат топлива. Ключевым аспектом тактического планирования является точность исходных данных, к которым относятся: план рейсов транспортных судов; ледокольный флот, которым располагает оператор; долгосрочные ледовые прогнозы. Наибольшая степень неопределенности характерна для последнего фактора, причем известно, что по ряду объективных причин точность долгосрочных ледовых прогнозов не может быть высокой. Тем не менее необходимость планирования на среднесрочном временно́м горизонте является бесспорной. Это обусловлено тем, что на основе тактического плана будет формироваться общее видение очередной ледовой навигации, являющейся основой для принятия основных организационных решений, которые требуют достаточной заблаговременности. В качестве инструментов решения задач тактического уровня используются методы исследования операций, оптимальной маршрутизации и логистического планирования (дискретная и комбинаторная оптимизация, линейное и нелинейное математическое программирование). Алгоритмы тактического планирования должны работать в режиме регулярного перепланирования с учетом вновь поступающих фактических данных.

Оперативное планирование охватывает временной интервал в несколько суток, что определяется горизонтом оправдываемости краткосрочных ледо- вых и синоптических прогнозов. Особенностью этого уровня является постоянное уточнение оперативного плана, т. е. перепланирование в онлайн-режиме с учетом поступающих данных мониторинга природных условий и положения судов. В результате формируется детальный оперативный план работы судов и ледоколов, пересчитываются оптимальные маршруты движения, а также анализируется соответствие текущего состояния транспортной системы опорному тактическому плану. Для решения этих задач необходимо интегрировать алгоритмы краткосрочных ледовых прогнозов, оптимальной маршрутизации и модели движения судов в нестационарных ледовых условиях. Достаточно важным информационным компонентом оперативного планирования работы ледоколов должна стать база знаний о приемах ледокольного сопровождения, которая позволит на основе нормативных наставлений и анализа архивных данных о лучших практиках ледокольной проводки определять расчетные параметры каравана (число проводимых судов, необходимое число и характеристики ледоколов) для каждого конкретного случая. Планирование на оперативном уровне достаточно сильно зависит от тактического плана. Это связано с тем, что оперативное планирование позволяет решать достаточно локальные задачи, но не дает возможности увидеть работу всей арктической морской транспортной системы в масштабах сезона или периода навигации, что составляет суть тактического планирования. Поэтому рационально организовать вложенную структуру системы планирования, напоминающую своеобразную «матрешку», 
в которой задачи оперативного уровня оказываются тесно интегрированы с тактическими. То есть оперативный план опирается как на данность на график рейсов судов, который, в свою очередь, регулярно уточняется на тактическом уровне. Аналогично для тактического плана «матрешкой» большего размера является модель стратегического типа, которая использует тактические планы в масштабах навигации, учитывающие весь накопленный оперативный опыт, для уточнения долгосрочных планов развития флота.

Таким образом, описанная постановка задачи планирования позволит отвечать на основные вопросы, актуальные для арктического судоходства с учетом комплекса влияющих факторов. Это напрямую определяет эффективность систем арктического транспорта и уровень организационно-технических рисков, обусловленных сложностью ледовой обстановки.

\section{Предложения по структуре Системы}

Современная информационно-аналитическая система для планирования судоходства в арктической зоне должна содержать элементы мониторингового ситуационного центра, экспертной системы поддержки принятия оперативных и тактических решений, а также базы данных и знаний предметной области. Таким образом, функциональные возможности предлагаемой информационно-аналитической компьютерной системы могут быть разделены на три основных направления: мониторинг, аналитика и поддержка принятия решений.

Функция мониторинга заключается в отслеживании, структурированном хранении и отображении оперативной и исторической информации о природных условиях и эксплуатации арктического флота. Основными объектами мониторинга являются маршруты и характеристики рейсов транспортных судов и караванов, примененные приемы ледокольной проводки, наблюдавшиеся природные условия, фактическая ледовая обстановка и ледовые прогнозы. К функции мониторинга также может быть отнесен и контроль фактического исполнения плана морских операций. Основным источником входной информации здесь являются данные мониторинга положения судов (AIS и другие системы), донесения с судов и данные судоходных компаний, а также внешние сервисы, предоставляющие сведения о фактической и прогнозируемой метеорологической и ледовой обстановке.

Функция аналитики состоит в статистической обработке объективных данных об эксплуатации арктического флота и вычислении сводных показателей эффективности морской транспортной системы в различных аспектах. В результате можно выполнять сравнение плановых и фактических характеристик операционной деятельности, что позволяет уточнять как сам план, так и методы его получения. Для формирования базы знаний о поведении судов различных типов в разнообразных ледовых услови- ях могут применяться механизмы машинного обучения. Основной источник входной информации для реализации функции аналитики - база данных операционной деятельности, формируемая в процессе мониторинга.

Функция поддержки принятия решений состоит в построении рациональных планов осуществления операций на тактическом и оперативном уровнях, т. е. создание планов работы ледоколов, определение рекомендованных маршрутов движения судов и караванов, расчет показателей экономической эффективности транспортных операций. В качестве входных данных используются результаты мониторинга, расчетные модули оптимального планирования операций и ледовой маршрутизации, информационные модели судов и модели их ходовых качеств.

Для реализации этих функций предлагается следующая укрупненная структура Системы (рис. 2). Она разработана в соответствии с принципами стандартной трехзвенной архитектуры распределенного программного решения, включающего интерфейсные модули (тонкие Web-клиенты), бизнес-логику (серверы приложений) и хранилища стационарных данных. Интерфейсные и логические блоки могут быть разделены на несколько информационных доменов: «Суда», «Рейсы», «Природа» и «Планирование». Модули, относящиеся к этим доменам, выделены на рис. 2 желтым, оранжевым, зеленым и синим цветами соответственно.

Назначение домена «Суда» состоит в описании характеристик транспортных судов и ледоколов как основных субъектов арктической навигации. Информационная модель (электронная карточка) судна содержит детальные сведения о его главных размерениях в различных состояниях загрузки, архитектурно-конструктивных особенностях, пропульсивном комплексе и энергетической установке. Это описание используется в качестве входных данных для модели движения судов и караванов во льдах и на чистой воде, которая, в свою очередь, позволяет определять различные параметры движения (достижимые скорости, расходы топлива, риск ледовых повреждений, объемы выбросов) для заданной погодной и ледовой обстановки. На базе этой модели можно производить оценки времени и показателей эффективности как автономных рейсов, так и караванных проводок, а также решать задачи ледового роутинга, т. е. определения наиболее рациональных маршрутов движения во льдах. Электронная карточка судна заполняется судовладельцем или фрахтователем как пользователем Системы. Однако при этом зачастую судовладельцу неизвестен ряд важных технических параметров судна, входящих в его информационную модель. Например, как правило, отсутствуют кривые действия гребных винтов, буксировочное сопротивление на тихой воде, коэффициенты взаимодействия винта с корпусом судна и др. В этой ситуации в электронную карточку может быть внесен только минимальный объем имеющей- 


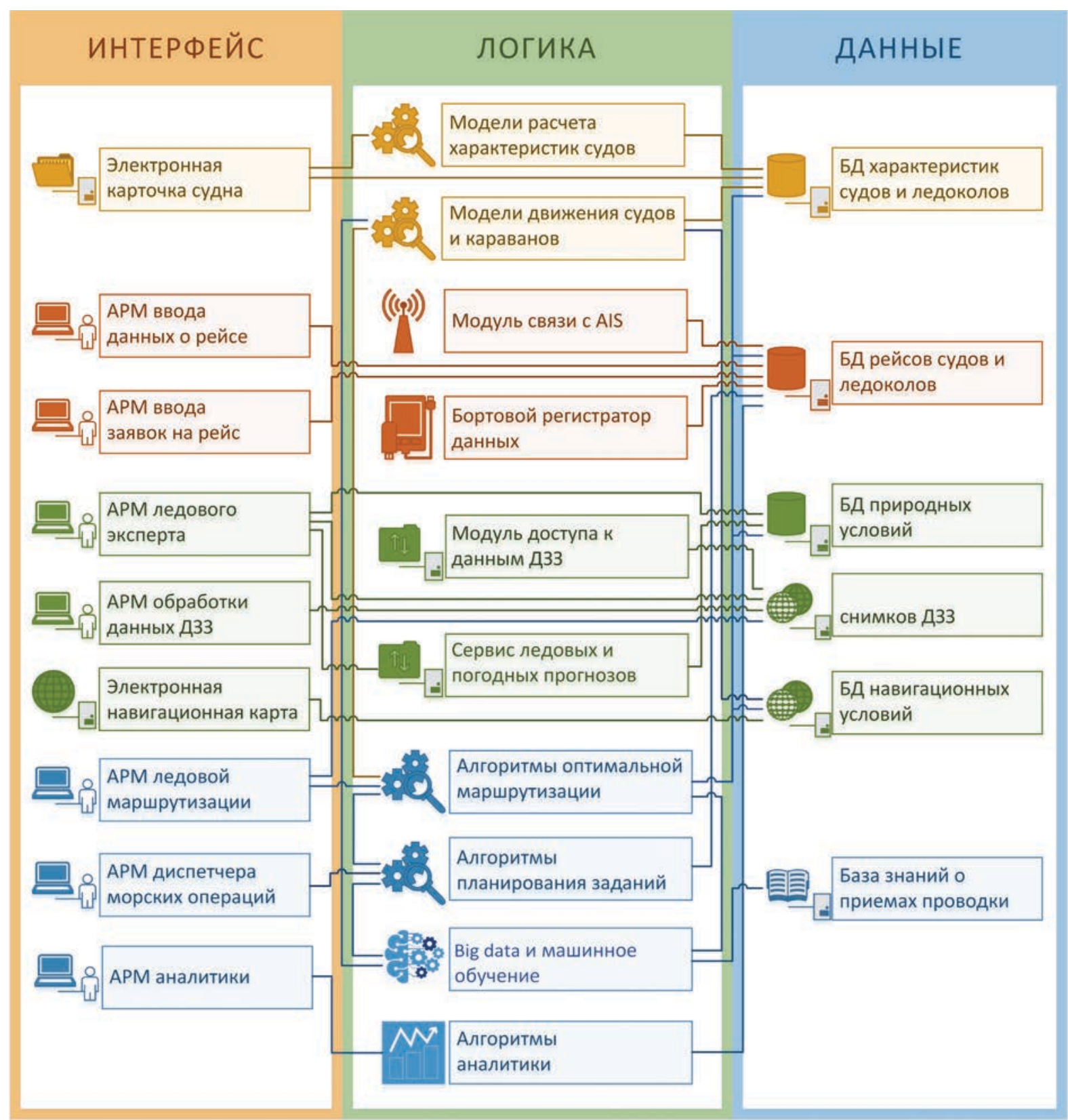

Рис. 2. Принципиальная структура и состав основных модулей Системы. Модули выделены цветом и объединены в следующие домены: «Судно» (желтый цвет), «Рейсы» (оранжевый), «Природа» (зеленый) и «Планирование» (синий)

Fig. 2. Basic layout and composition of the System main modules. The modules are highlighted in color and grouped into the following domains: “Ship” (yellow), “Passages” (orange), “Nature” (green), and “Planning” (blue)

ся информации (размерения, мощность двигателя и т. п.), а все другие параметры могут быть автоматически досчитаны специальными расчетными моделями для доопределения характеристик судов.

Домен «Рейсы» служит для хранения данных о рейсах транспортных судов и заданий ледоколов, а также содержит сведения о реальной практике судоходства. Основным информационным ядром этого домена является база данных рейсов, в которой хранится комплекс сведений о планируемых, текущих и завершенных рейсах судов и ледоколов, т. е. упорядоченный во времени журнал всех характери- стик движения, различных операций, эксплуатационных параметров и условий внешней среды. Пополнение информации о конкретном рейсе может производиться как в ручном, так и в автоматическом режиме. В первом случае источником информации служит автоматизированное рабочее место (АРМ) для ввода оперативной информации о текущем рейсе (аналог диспетчерского донесения с судна ДПР). Помимо этого в ручном режиме также может производиться ввод заявок на рейс (заявка подается эксплуатантом транспортного судна через webинтерфейс перед его входом в арктические воды). 
Во втором случае информация о текущем рейсе попадает в базу данных в ходе работы автоматических сервисов: модуля связи с единой системой идентификации судов (AIS) и специального программноаппаратного измерительного комплекса на борту судна (получение информационных пакетов по стандартизованному протоколу обмена). Ориентировочный перечень параметров рейса, которые могут измеряться данным модулем, приведен на рис. 3. Создание бортового регистратора и его адаптация для использования на всех судах, осуществляющих регулярное судоходство в Арктической зоне России, позволит получать большие объемы оперативной информации о движении судна и внешней среде. Эти данные могут использоваться для решения сразу нескольких важных задач, таких как уточнение ледовой обстановки и улучшение качества ледовых прогнозов, разработка и верификация моделей движения судов и караванов во льдах, повышение качества поддержки оперативных решений.

Домен «Природа» предназначен для описания, хранения и отображения параметров окружающей среды. Он содержит как элементы статической информации - электронные навигационные карты и базу данных навигационных условий, так и компоненты для оперативного мониторинга и прогноза динамики погодной и ледовой обстановки. Важнейшим источником данных о ледовых условиях в регионе в последнее время становятся спутниковые снимки дистанционного зондирования Земли (ДЗ3). Поэтому разрабатываемая Система должна включать в себя весь комплекс инструментов для работы с соответствующими сервисами: модули связи с поставщиками спутниковой информации (снимки в различных спектральных диапазонах, радиолокационные снимки и т. д.), собственные инструменты для первичной обработки спутниковых снимков (геопривязка, фильтрация, выбор проекции, отбор наиболее информативных снимков, очистка от облачности и т. д.), а также АРМ ледового эксперта. Последний предназначен для комплексного анализа оперативных спутниковых данных и электронных карт текущих ледовых условий. Функционал АРМ ледового эксперта может быть расширен и дополнен удаленным сервисом АРМ «Ледовый прогнозист», задачей которого является составление оригинальных прогнозных карт развития ледовой обстановки с заблаговременностью 3-5 сут. Для этого необходимо использование синоптических прогнозов и расчетных прогностических моделей динамики и термики (нарастания) льда. Отметим, что АРМ ледового прогнозирования и ледового эксперта могут быть реализованы путем интеграции и усовершенствования существующего функционала информационной системы «Север» (см. далее).

Интеллектуальным ядром разрабатываемой системы планирования арктического судоходства должны стать сервисы, объединенные в домен «Планирование» и связанные с алгоритмами авто- матической поддержки решений. В первую очередь под этим понимаются сервисы автоматического планирования работы ледокольного флота на тактическом уровне (алгоритмы планирования заданий) и определения оптимальных маршрутов движения судов и караванов на оперативном уровне (ледовая маршрутизация или ледовый роутинг). Более отдаленная перспектива - возможность использования современных инструментов анализа больших данных и методов машинного обучения для верификации существующих и разработки принципиально новых моделей движения судов и караванов во льдах, а также для формирования и поддержки в актуальном состоянии специализированной базы знаний о принципах арктического судоходства и конкретно о приемах ледокольного сопровождения. Эта база знаний должна формироваться как на основе анализа лучших практик, применяемых в реальности, так и путем формализации многочисленных регламентов и нормативных документов. Безусловно, успешная реализация технологий машинного обучения возможна только при условии накопления значительного объема согласованной и структурированной фактической информации в соответствующих базах данных Системы (БД параметров рейсов, БД природных условий и т. д.). Это станет возможно через несколько лет после ввода Системы в эксплуатацию.

\section{Основные научно-методические сложности}

Практическая реализация Системы потребует серьезной межотраслевой кооперации, а также определенной этапности разработки и внедрения. Часть указанных на рис. 2 сервисов может быть реализована путем доработки и расширения уже существующих технологий и программных решений. Однако некоторые блоки, которые имеют большое практическое значение, могут быть реализованы только в ходе специальной разработки, подкрепленной соответствующими научно-прикладными исследованиями и натурными данными. Отметим три основные группы задач из этой сферы.

Существенную научно-методическую проблему представляет собой пространственное логистическое планирование работы судов и ледоколов на тактическом и оперативном уровнях, являющееся главным интеллектуальным элементом предлагаемой Системы. Сложность заключается в отсутствии готовых программных решений и однозначных алгоритмических подходов для решения этих задач в полной математической постановке. Даже такая задача оперативного уровня, как поиск оптимального маршрута для автономного рейса судна во льдах, достаточно сложна, поскольку в ней должен быть учтен нестационарный характер среды, а также множественность ограничений и альтернативные критерии оптимизации. Размерность этой задачи возрастает в разы, если в нее включить возможность ледокольного сопровождения, так как при 


\section{Окружающая среда}

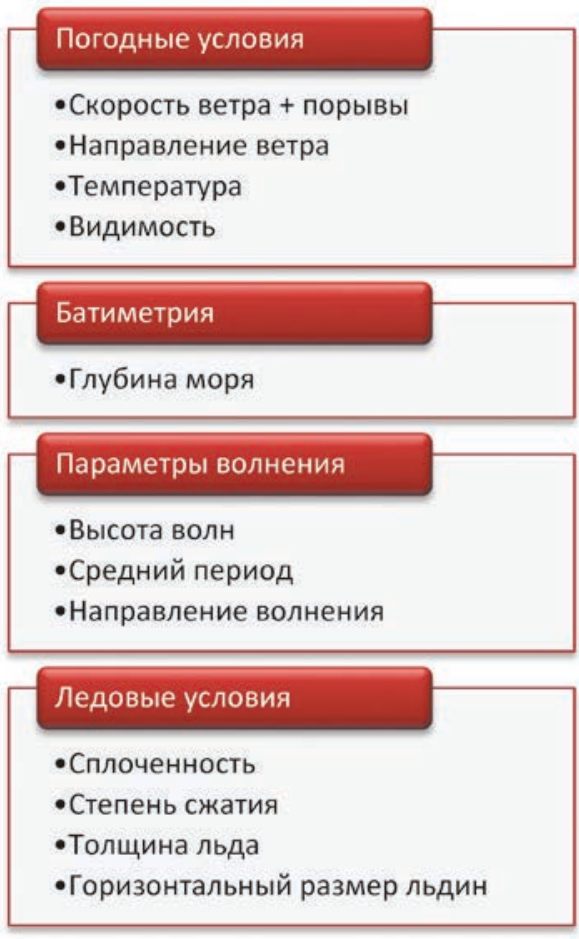

\section{Данные по судну}

\section{Параметры загрузки судна}

-Осадка носом и кормой

-Возвышение центра тяжести

\section{Параметры движения}

•Истинный курс

- Направление движения с учетом сноса

-Координаты и скорость хода

-Угловая скорость на правом и левом бортах

-Ускорения на мостике / на баке

-Период и размах бортовой / килевой качки

Винто-рулевой комплекс

- Обороты и шаг каждого винта

-Обороты и мощность каждого подрул. устройства

-Углы перекладки рулей / ориентация колонки

Энергетическая установка

-Обороты и мощность кажого двигателя

•Текущий и суточный расход топлив всех типов

Рис. 3. Ориентировочный перечень параметров, которые следует измерять бортовым регистратором данных рейса во льдах Fig. 3. Preliminary list of parameters to be measured by the onboard data recorder of ship voyage in ice

этом приходится дополнительно учитывать, что на некоторых участках судно может двигаться самостоятельно, а на других - под проводкой ледокола. Однако поиск оптимального маршрута движения судна с ледоколом или без него - это лишь наиболее понятная составляющая общей проблемы тактического планирования. Последняя заключается в формировании расписания рейсов судов и ледоколов, а также в планировании состава караванов, дат и мест их сбора и роспуска. С математической точки зрения эта проблема может быть отнесена к классу сложных комбинаторных NP-полных задач, для которых доказано принципиальное отсутствие эффективного универсального алгоритма, позволяющего найти строго оптимальное решение за разумное время. Более того, при планировании арктического судоходства приходится сталкиваться с дополнительными усложняющими факторами. Во-первых, это необходимость искать решение в условиях сильной неопределенности ледовой обстановки, которая в масштабах периода навигации может быть спрогнозирована лишь самым приблизительным образом, например на основе года-аналога. Во-вторых, в отличие от задач логистического планирования автомобильных или железнодорожных перевозок, где дороги представляют собой естественные ребра графа оптимизации, морские перевозки осуществляются в непрерывном пространстве (например, местом сбора каравана может быть назначена про- извольная географическая точка). В-третьих, повышенная сложность и риск судоходства во льдах выдвигают специфические требования к резервированию ресурсов для обеспечения возможности разрешения любых инцидентов, возникающих на оперативном уровне (зажатие судна во льдах, поломки движителей и т. п.). Поэтому применительно к задаче тактического планирования в данных условиях речь может идти о нахождении не строго оптимальных, а только субоптимальных и устойчивых решений. Перспективным инструментом решения могут служить современные эвристические подходы, такие как алгоритмы муравьиных колоний, генетические алгоритмы или нейронные сети.

Вторая группа задач заключается в повышении информативности, точности, скорости получения и заблаговременности оперативных ледовых прогнозов. В настоящее время такие прогнозы предоставляются обычно один раз в три-пять дней и только для заданных морей. Необходимые в масштабах всей Арктики ледовые прогнозы, создаваемые с использованием численной модели совместной циркуляции атмосферы, океана и льда, не являются бесплатными. Для их получения в случаях, когда акватория закрыта облачностью, необходимы радиолокационные спутниковые снимки текущего состояния ледового покрова в высоком разрешении, характеризуемые высокой стоимостью. Помимо этого требуется работа ледовых экспертов по 
дешифровке снимков, которая не только требует оплаты, но и занимает значительное время (по меркам оперативного ледового прогноза). Определенное время также требуется для работы численной модели, описывающей динамику и термику ледяного покрова, что заставляет искать компромисс между скоростью получения данных и их детализацией. Если обратиться к научно-прикладным аспектам прогнозирования, то одна из основных проблем состоит в том, что современные ледовые прогнозы для зимнего периода не содержат ряда важных характеристик льда, которые в обязательном порядке учитываются в настоящее время при автоматизированной прокладке маршрута ледовым экспертом. Одной из таких важных характеристик являются нарушения сплошности ледяного покрова (разрывы, трещины, каналы), ориентация, расположение и периоды существования которых во многом определяют маршруты плавания судов [6]. Отсутствие данных о разрывах в составе оперативных карт ледовой обстановки и ледовых прогнозов затрудняет решение задачи ледовой маршрутизации в автоматическом режиме. Поскольку эта задача является одним из основных составных элементов более масштабных задач пространственного логистического планирования работы судов и ледоколов на тактическом и оперативном уровнях, то и решение последних также оказывается затруднительным. Именно по причине сложности обеспечения полной автоматизации процессов планирования рейсов и роутинга судов во льдах на данном этапе в составе схемы Системы предусмотрены береговые АРМ ледового эксперта и ледовой маршрутизации.

Третья группа научно-прикладных проблем связана с повышением точности расчетной модели движения судов и караванов во льдах. Суть вопроса состоит в том, что лед с точки зрения судоходства характеризуется множеством параметров, влияющих на скорость судна. Для каждой возрастной градации льда (обычно в однородной ледовой зоне выделяют не более трех градаций) различают собственно возраст, сплоченность и форму льда. Дополнительно ледовые условия в регионе характеризуются торосистостью, заснеженностью, разрушенностью, интенсивностью сжатия и наличием разрывов. Большинство этих параметров не подлежит объективному измерению, они определяются гидрологом на глаз, а балльная система классификации подразумевает достаточно широкие пределы варьирования параметров. Например, возрастная градация однолетнего льда средней толщины объединяет значения от 70 до 120 см, тогда как эта вариация может оказать принципиальное влияние на скорость судна. Помимо этого движение судов во льдах имеет избирательный характер, когда судоводитель осуществляет своего рода «микророутинг», обходя тяжелые льдины и двигаясь по наиболее легким. Это приводит к необходимости различать ледовые условия в регионе движения (а именно они приводятся на ледовой карте и используются для прогнозирования показателей рейса) и ледовых условий непосредственно на пути плавания судна, которые и определяют фактические скорости хода. Bce это крайне затрудняет создание физически обоснованных моделей движения судов в ледовых условиях, и в особенности в наиболее важном для арктического судоходства случае, когда в регионе движения имеется лед разных возрастных градаций. В этих условиях для определения параметров движения судов и караванов отечественные специалисты еще в 1970-х годах предложили использовать эмпирико-статистические модели, полученные в ходе регрессионного анализа данных систематических наблюдений на борту судов [7]. Эти модели, созданные для судов и ледоколов водоизмещением до 15-20 тыс. т, нуждаются в корректировке [8] применительно к современным ледовым транспортным судам, водоизмещение которых достигает 100-120 тыс. т. В последнее время появилась тенденция развития принципов эмпирико-статистического подхода на новом технологическом уровне с использованием технологий больших данных и машинного обучения [9]. Эти технологии позволят наиболее точно определять параметры движения судов с учетом всего комплекса влияющих факторов, куда входят не только характеристики льда и другие технические факторы, но и такие субъективные аспекты, как, например, квалификация и личные предпочтения судоводителя. Для реализации решений в предложенной структуре Системы предусмотрены соответствующие блоки и модули. Например, бортовой регистратор данных рейса необходим для получения больших объемов натурной информации о параметрах движения судна и окружающей ледовой обстановке.

Очевидно, что все указанные группы научно-прикладных задач тесно связаны. Невозможно повысить качество логистического планирования, не имея достоверных данных о состоянии ледяного покрова и точных моделей движения судов. Однако соответствующие разработки требуют целенаправленных и длительных усилий целого ряда организаций и специалистов. Поэтому интеллектуальная начинка описываемой Системы может разрабатываться и совершенствоваться в течение достаточно длительного времени.

\section{Имеющийся научно-технический \\ задел отечественных компаний}

Несмотря на описанные выше научно-методические сложности, в настоящее время имеется серьезный задел для практической реализации Системы. Существует много компаний, способных поставлять оборудование и программное обеспечение для реализации функций контроля и учета в ситуационных центрах работы флота. Однако далее мы отметим только специализированные отечественные разработки, которые наиболее ин- 
тересны с точки зрения практической реализации Системы.

1. Система адресного гидрометеорологического обеспечения судоходства в Арктике создана на базе Центра «Север», расположенного в ФГБУ «Арктический и антарктический научно-исследовательский институт» (ААНИИ). Ледово-информационная система была разработана в 1980-х годах [10], практическая эксплуатация стартовала в середине 2000-х годов, а в 2006-2007 гг. была выполнена ее модернизация [11]. Сегодня она успешно применяется В ААНИИ для регулярного информационного обеспечения плавания судов в рамках ресурсодобывающих проектов «Норильский никель», «Сахалин-1», «Сахалин-2», «Ямал СПГ» и др., а также для разовых проводок транзитных судов и ледоколов. Результатом работы этого сервиса являются оперативные ледовые карты, численные прогнозы динамики льда и рекомендации по выбору оптимального маршрута плавания во льдах. В структуру системы входят многие элементы из схемы, приведенной на рис. 2, относящиеся к получению и обработке данных Д33, базам данных природных и навигационных условий, работе ледовых экспертов. Таким образом, эта система предназначена для гидрометеорологического обеспечения судоходства.

2. Ряд научно-прикладных разработок, которые могут быть непосредственно задействованы в создании расчетно-аналитических блоков предлагаемой Системы, был выполнен во ФГУП «Крыловский государственный научный центр» (КГНЦ). Первая разработка - компьютерная технология для комплексного имитационного моделирования морских транспортных систем (МТС) [5] - базируется на интеграции технологий и алгоритмов из области геоинформационных систем, динамического имитационного моделирования, судостроительных дисциплин и объектно-ориентированного программного подхода. В имитационной модели объединены транспортные (работа порта, накопление грузов, движение судов и т. п.), природные (зарастание ледового канала в припае) и технологические (работа бурового комплекса платформы) процессы. В 2014-2018 гг. с использованием этой технологии был выполнен ряд научно-прикладных работ для крупных индустриальных заказчиков [12]. В рамках данных исследований анализировались на стратегическом уровне МТС, при этом производилось тактическое планирование рейсов, а в ряде проектов в модель интегрировались расчетные алгоритмы оперативного планирования. Другой разработкой КГНЦ является созданный в 2016 г. опытный образец комплексной системы управления ледовой обстановкой (КСУЛО), предназначенный для проведения морских операций во льду с буровыми и добычными платформами [13]. КСУЛО представляет собой комплекс технических средств для мониторинга ледовой обстановки, получения прогнозов динамики ледовых условий, данных о пози- ции и параметрах движения судов в районе работ и отображения оперативной информации на платформе, судовом терминале и в береговом центре управления в режиме реального времени для поддержки принятия судоводителями оперативных решений. Комплекс в целом и отдельные его элементы несколько раз использовались в натурных условиях. Последней разработкой специалистов КГНЦ, имеющей отношение к расчетным и плановым блокам Системы, является макет программного приложения для сопоставления и анализа альтернативных методов роутинга судов во льдах с учетом ледокольного сопровождения. Приложение создавалось в рамках работ, поддержанных грантом Российского научного фонда № 17-79-20162 «Разработка технологии тактического и оперативного планирования и управления работой ледоколов и судов ледового плавания в условиях круглогодичной навигации по трассам Северного морского пути».

3. Бортовые средства мониторинга ледовой обстановки и регистрации данных рейса создавались в рамках нескольких проектов. В начале $2000-x$ годов в ААНИИ был создан прототип автоматизированного телевизионного комплекса для регистрации толщин льда по развернутым вдоль борта фрагментам ледяного поля [14]. В состав комплекса входит камера для видеофиксации льда в районе борта и программные компоненты. Подбор информативных кадров, на которых видны развернутые льдины, осуществляется автоматически. Комплекс успешно использовался сотрудниками ААНИИ в ряде рейсов научно-исследовательского судна «Академик Федоров» и других судов. В 2009 г. также в ААНИИ была реализована идея и создан прототип автоматизированного телевизионного измерительного комплекса для определения степени сжатия ледового покрова по скорости изменения ширины ледового канала за кормой судна [15]. В рамках проекта КСУЛО в КГНЦ были реализованы автоматические программно-аппаратные средства для регистрации толщин льда и степени сжатия ледяного покрова в режиме реального времени без участия эксперта [16]. Помимо этого в рамках проекта КСУло были созданы средства для видеофиксации и автоматического распознавания показаний индикаторов судовых приборов. Такие технические решения необходимы для считывания и сохранения данных о параметрах движения судна без подключения к судовой автоматизированной системе управления, доступ к которой, как показывает практика, серьезно ограничен.

\section{Заключение}

Детали изложенной в настоящей статье концепции создания централизованной информационной системы для планирования работы флота в Арктике, безусловно, подлежат дальнейшему обсуждению и корректировке в ходе проектирования, разработки и внедрения. Однако принципиальная цель создания Системы представляется сформулированной 
достаточно четко. Она заключается в повышении экономической эффективности работы судов в Арктике за счет интеллектуального планирования работы флота с использованием современных информационных технологий. Сфера применения предлагаемой Системы - это главным образом повышение безопасности и эффективности арктического судоходства, а не интеграция интермодальной логистики и документальное сопровождение грузоперевозок. Это разграничивает сферы компетенций потенциального пользователя Системы, с одной стороны, и судоходных компаний - с другой, поскольку последние ориентированы именно на обеспечение грузоперевозок. Разработка и внедрение Системы в практическую эксплуатацию представляют собой длительные и трудоемкие процессы, которые потребуют кооперации и совместных усилий целого ряда государственных организаций и частных компаний. Однако именно в сфере централизованного планирования работы флота в Арктике заключен один из основных ресурсов для повышения экономической эффективности грузоперевозок и роста привлекательности СМП для транзитного плавания.

\section{Литература}

1. Vauraste T. Icepool - Holistic use of global icebreaker fleet // Maritime cluster in the Baltic Sea region and beyond. - [S. I.], 2016. - P. 104-105

2. International Code for Ships Operating in Polar Waters. - Guidance on Methodology for assessing operational capabilities and limitations in ice. - Polar Operational Limit assessment Risk Indexing System (POLARIS). - [S. I.], 6 June 2016. — MSC.1/Circ.1519. 3. Christiansen M., Fagerholt K., Nygreen B., Ronen D. Maritime Transportation // Handbooks in Operations Research and Management Science / C. Barnhart, G. Laporte (eds.). - North Holland, Amsterdam, 2007. - P. 189-284.

4. Бахарев А. А., Косоротов А. В., Крестьянцев А. Б. и Әр. Иерархия уровней принятия решений в имитационном моделировании морских перевозок // Тр. конф. ИММОД-2015. - Т. 1. - М.: ИПУ РАН, 2015. - C. 34-39.

5. Таровик О. В., Топаж А. Г., Крестьянцев А. Б., Кондратенко А. А. Моделирование систем арктического морского транспорта: основы междисциплинарного подхода и опыт практических работ // Арктика: экология и экономика. - 2017. - № 1 (25). - C. 86-101.

6. Фролов С. В. Влияние ориентации нарушений сплошности льда на эффективность движения су- дов в арктическом бассейне в летний период // Проблемы Арктики и Антарктики. - 2013. - № 3 (97). - C. 35-45.

7. Adamovich N. M., Buzuyev A. Ya., Fedyakov V. E. The empiric model of vessel movement in the ice and generalization of the experience of the model usage in hydrometeorological support of shipping in the Arctic // Proceedings of POAC-1995. - Vol. 2. - Murmansk, 1995. - P. 30-40.

8. Brovin A. I., Klyachkin S. V., Bhat S. U. Application of an empirical-statistical model of ship motion in ice to new types of icebreakers and ships // Proceedings of OMAE-1997. - Vol. 4. - Yokohama, Japan, 1997. - P. 43-49.

9. Montewka J., Sinclair H., Kujala P. et al. Modelling ship performance in ice using Bayesian Networks // Proceedings of POAC-2013. - Espoo, Finland, 2013. - 12 p.

10. Бушуев А. В., Волков Н. А., Гудкович 3. М. u др. Автоматизированная ледово-информационная система для Арктики (АЛИСА) // Тр. ААНИИ. - 1977. - Т. 343. - С. 29-47.

11. Миронов Е. У., Ашик И. М., Бресткин С. В., Смирнов В. Г. Адаптируемый комплекс мониторинга и прогнозирования состояния атмосферы и гидросферы // Проблемы Арктики и Антарктики. - 2009. - № 3 (83). - С. 88-97.

12. Таровик О. В., Топаж А. Г., Крестьянцев А. Б. и др. Комплексная имитационная модель морской транспортно-технологической системы платформы «Приразломная» // Арктика: экология и экономика. 2017. — № 3 (27). - С. 86-103.

13. Рыбий В. В., Казунин Д. В., Тимофеев О. Я. и др. Российская ледовая информационная система (ЛИС) - залог успешного освоения Арктики // Мор. вестн. - 2016. - № 4 (60). - С. 63-67.

14. Фролов С. В., Клейн А. Э., Третьяков В. Ю. Результаты использования цифрового телевизионного комплекса для измерений толщины льда в Арктическом бассейне в 2004-2005 гг. // Проблемы Арктики и Антарктики. - 2007. - № 1 (75). С. $123-127$

15. Третьяков В. Ю., Фролов С. В., Клейн А. Э. Методика расчета скорости сложения канала в ледяном покрове по данным телевизионных снимков // Метеор. вестн. - 2010. - № 2 (7). - С. 12-29.

16. Проняшкин А. А., Карулин Е. Б., Казанцев М. А. Ледовая информационная система для Арктического шельфа // Тр. Междунар. конф. Offshore Marintec Russia-2018. 2-5 октября 2018 г. - СанктПетербург, 2018.

\section{Информация об авторах}

Тимофеев Олег Яковлевич, доктор технических наук, заместитель генерального директора по судостроению и морской технике - начальник 5 отделения, ФГУП «Крыловский государственный научный центр» (196158, Россия, Санкт-Петербург, Московское ш., 44), e-mail: o_timofeev@ksrc.ru.

Таровик Олег Владимирович, кандидат технических наук, старший научный сотрудник, ФГУП «Крыловский государственный научный центр» (196158, Россия, Санкт-Петербург, Московское ш., 44), e-mail: tarovik_oleg@mail.ru. 
Топаж Александр Григорьевич, доктор технических наук, ведущий научный сотрудник, ФГУП «Крыловский государственный научный центр» (196158, Россия, Санкт-Петербург, Московское ш., 44), e-mail: alex.topaj@ gmail.com.

Миронов Евгений Уарович, доктор географических наук, главный научный сотрудник - заведующий отделом ледового режима и прогнозов, ФГБУ «Арктический и антарктический научно-исследовательский институт» (199397, Россия, Санкт-Петербург, ул. Беринга, 38), e-mail: mir@aari.ru.

Фролов Сергей Викторович, заведующий лабораторией изучения ледового плавания, ФГБУ «Арктический и антарктический научно-исследовательский институт» (199397, Россия, Санкт-Петербург, ул. Беринга, 38), e-mail: svf@aari.nw.ru.

Буянов Александр Сергеевич, кандидат экономических наук, заместитель генерального директора по научной работе, по развитию, экономике и экологии морского транспорта, АО «Центральный ордена Трудового Красного Знамени научно-исследовательский и проектно-конструкторский институт морского флота» (191015, Россия, Санкт-Петербург, Кавалергардская улица, 6A), e-mail: buyanovas@cniimf.ru.

Горбачев Максим Александрович, кандидат технических наук, руководитель отдела программной разработки, ООО «Научный логистический центр» (115172, Россия, Москва, Гончарная ул., 28, стр. 2), e-mail: mg@n-I-c.ru.

Бенгерт Александр Александрович, заместитель начальника управления, Дирекция Северного морского пути государственной корпорации «Росатом» (119017, Россия, Москва, ул. Большая Ордынка, 24), e-mail: aabengert@rosatom.ru.

\section{Библиографическое описание данной статьи}

Тимофеев О. Я., Таровик О. В., Топаж А. Г. и др. Концепция централизованной информационной системы для планирования работы флота в Арктике // Арктика: экология и экономика. - 2019. — № 1 (33). C. 129-143. — DOI: 10.25283/2223-4594-2019-1-129-143. 